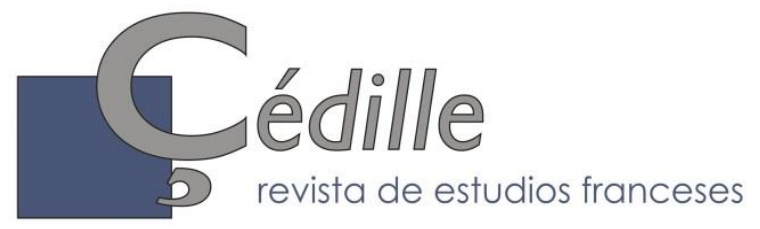

ISSN: 1699-4949

no 20 (otoño de 2021)

Varia

\title{
Consideraciones sobre el profetismo en los escritos de Joseph de Maistre
}

\author{
María Luisa GuerRero Alonso \\ Universidad Complutense de Madrid \\ mlguerre@ucm.es \\ https://orcid.org/o000-0002-0524-9206
}

\section{Resumen}

La relación de los ensayos de Joseph de Maistre con el profetismo ha constituido un tema privilegiado en los estudios dedicados al autor. El artículo revisa y matiza dicho enfoque distinguiendo dentro de la obra maistriniana los caracteres teóricos de la perspectiva profética en tres etapas de análisis: las opiniones del escritor sobre la visión y el hacer proféticos, los testimonios que singulares contemporáneos formularon sobre el alcance profético de sus obras y, por último, la consideración de su discurso como discurso profético, tanto por determinados rasgos retóricos como por su temática, centrada en la evolución de las propuestas de su profetismo político. La investigación concluye resaltando que la noción de impulso profético es la clave cohesionadora del corpus maistriniano.

Palabras clave: Oráculo, Visión profética, Providencia, Profetismo político.

\section{Résumé}

La relation entre les essais de Joseph de Maistre et le prophétisme a été un thème privilégié dans les études consacrées à l'auteur. Cet article examine et nuance cette approche en distinguant dans l'œuvre maistrinienne les caractères théoriques du prophétisme en trois étapes d'analyse : les opinions de l'écrivain sur la vision et l'action prophétiques, les témoignages que des contemporains singuliers ont formulés sur la portée prophétique de ses œuvres et, enfin, la considération de son discours en tant que discours prophétique, aussi bien pour certains traits rhétoriques que pour sa thématique, centrée sur l'évolution de son prophétisme politique. La recherche conclut en soulignant que la notion d'élan prophétique est l'élément clé de la cohésion du corpus maistrinien.

Mots clé : Oracle, Vision prophétique, Providence, Prophétisme politique.

\begin{abstract}
The relationship of Joseph de Maistre's essays with prophetism has been a central theme in the studies dedicated to the author. This article reviews and qualifies this approach by distinguishing within Maistre's work the theoretical characteristics of the prophetic perspective in three stages of analysis: the writer's opinions on prophetic vision and prophetic action, the testimonies that singular contemporaries formulated on the prophetic scope of his works and, finally, the
\end{abstract}

*Artículo recibido el 15/09/2021, aceptado el 20/10/2021. 
consideration of his discourse as a prophetic discourse, both for certain rhetorical features and for its subject matter, centered on the evolution of the proposals of his political prophetism. The research concludes by highlighting that the notion of prophetic impulse is the key to the cohesion of the Maistrinian corpus.

Key words: Oracle, Prophetic visión, Providence, Political prophecy.

\section{Introducción}

Interesarse por la figura de Joseph de Maistre resulta inevitable cuando se trata de estudiar la perspectiva profética en el ámbito del pensamiento y de la creación literaria y artística occidentales. En efecto, ya desde la publicación de su primer ensayo, Considérations sur la France (1797), la persona, el discurso y el mensaje del pensador saboyano se han venido relacionando con términos como profeta, profético o profetismo; de este modo, tanto el contenido de sus escritos como la enunciación de los mismos han contribuido a hablar de su "frénésie prophétique" (Cioran, 1977), a dibujarle un perfil de autor "étonnamment biblique, [qui] se comporte comme un prophète de l'Ancien Testament", (Sollers, 2010) o, incluso, a hacerle exponente de un "prophétisme qui donne des nausées", tal y como lo calificaron ciertas opiniones recogidas por Georges Bernanos (1931) en su ensayo La Grande-Peur des Bien-Pensants. El caso es que este "profeta de nuestra época, notable y aterrador" (Berlin, 1992) se refirió sólo una vez a sí mismo como tal, con la expresión "prophète allogrobe" en el marco de su correspondencia privada ${ }^{1}$; esta circunstancia contrasta con los abundantes testimonios de lectores que sí lo encuadraron muy pronto y lo han seguido considerando después dentro de esa perspectiva profética.

$\mathrm{Al}$ vertebrarse esta investigación en la relación del pensamiento maistriniano con el profetismo, se impone precisar en qué sentido se utilizará dicho concepto. En primera instancia, seguiremos la definición por extensión de este término que recoge el Trésor de la langue française informatisé, esto es, "tendance au comportement de ceux qui, se fondant sur des vues a priori, bien que sur des donnés de fait, annoncent un avenir plus o moins éloigné. Prophétisme marxiste"2 En este sentido y tal como reconoce el filósofo francés Julien Freund, dicha definición representaría un empleo secularizado del término profetismo, noción de origen estrictamente religioso que ha sufrido a lo largo de la historia una deriva semántica

\footnotetext{
${ }^{1}$ Esta referencia se incluye en la carta del 28 de mayo de 1819 dirigida a la Duquesa de Cars, donde J. de Maistre, se tilda a sí mismo de "prophète allogrobe" declarando su fe en el resurgir de Francia: "La France se rétablira parfaitement; elle sera refaite comme elle a été faite, par le clergé et par la noblesse" (De Maistre, $1886: 164$ ).

${ }^{2}$ Esta definición es una adaptación de la acuñada por el filósofo y sociólogo Paul Foulquié en Vocabulaire des Sciences sociales (1977).
} 
y conceptual por analogía, procedimiento éste especialmente fructífero en el terreno de la Sociología política:

Si elle a été utilisée dans le vocabulaire politique, c'est que l'on a estimé que certains aspects de la démarche politique présentent, sous certains rapports, des analogies significatives, sous une forme sécularisée, avec le prophétisme proprement religieux (Freund, 1982: 373).

En efecto, el profetismo maistriniano se concreta en gran medida en una tendencia constante al vaticinio de una Francia muy distinta tanto a la del momento revolucionario en el surgieron sus primeras previsiones como a la diseñada posteriormente por la restauración monárquica protagonizada por Luis XVIII. En De Maistre, esta continuidad del discurso predictivo de índole sociopolítica se engarza, además, en el origen transcendente que el autor le otorga y que, a la vez, lo explica y argumenta, aspecto éste que singularizará las predicciones maistrinianas dentro del ámbito del profetismo político. Por este motivo y por otros, como el especial interés del ensayista saboyano por la figura de los profetas bíblicos, también nos ocuparemos de relacionar la visión ideológica del autor con el profetismo religioso, el cual "par essence repose donc sur une élection, à savoir le choix par lequel la divinité investit un homme de la capacité de révéler le dessein surnaturel" (Freund, 1990: 62).

A partir de las precisiones anteriores sobre la relación de la obra y la figura de Joseph de Maistre con las distintas vertientes del concepto de profetismo, se han diseñado las etapas por las que discurrirá la investigación objeto de estas líneas. El primer punto de interés lo constituye las consideraciones del escritor sobre el profetismo tal y como quedaron expresadas en sus escritos, entre los que hemos seleccionado por su pertinencia Considérations sur la France y Les Soirées de Saint Pétersbourg. Entretiens sur le gouvernement temporel de la Providence (post, 1821); tras esta exposición, se describirán algunos de los testimonios de tempranos lectores de su obra con el fin de acercarnos a la génesis de la asociación de su figura y quehacer intelectual con el carácter profético, rasgo de amplia incidencia en la recepción de este escritor, como ya se ha señalado al inicio de estas páginas Por último y tras analizar algunas de estas opiniones lectoras y su repercusión, volveremos a acercarnos a los textos antes mencionados para sacar a la luz ciertos caracteres hermenéuticos y poéticos que adquiere esa perspectiva profética que los lectores de diversas épocas han reclamado para el mensaje y el estilo del pensador saboyano. En definitiva, el objetivo último de esta investigación es caracterizar, precisar y matizar las modulaciones del profetismo en la voz ensayística de Joseph de Maistre, recurriendo para ello tanto a sus propias reflexiones sobre la cuestión como a las que otros autores han realizado a partir de sus escritos. 


\section{Joseph de Maistre considera a los profetas}

El recorrido cronológico de los escritos del Joseph de Maistre ofrece al lector un empleo esporádico de la referencia profética, fundamentalmente concretada en diversas citas del Libro de Isaías y en dos alusiones a los Salmos del rey David (XXI y LXXI), las cuales se unen a otras presencias textuales de autores clásicos y contemporáneos, ya sea para apoyar en ellos su argumentación, ya sea para refutarlos con su discurso. Habrá que esperar a Les Soirées de Saint-Pétesbourg. Entretiens sur le gouvernement temporel de la Providence (1821) para que De Maistre incluya en su ejercicio reflexivo una referencia más amplia al profetismo, centrada en una descripción precisa del conocimiento profético. Constituye ésta el núcleo temático de la velada décimo primera de la obra3.

Recordemos que los once capítulos del mismo ("les soirées") y la serie de notas que los acompañan se constituyen como la crónica de once veladas durante las cuales dialogan tres personajes - un caballero francés, un senador ruso-griego y un conde, alter-ego éste de Joseph de Maistre-. En el transcurso de estas largas conversaciones:

L'auteur s'attaque à tous ces pourquoi, les perce en tous les sens et les tourmente : il en fait jaillir de belles visions. La forme d'entretien mène à chaque pas la variété, l'imprévu, met en jeu l'érudition, justifie la boutade et le sarcasme, tout en laissant jour à l'effusion et à l'éloquence (Sainte-Beuve, 1862: 448).

Este largo texto dialogado fue compuesto entre 1802 y 1817 , periodo que nuestro autor pasó en San Petersburgo como ministro plenipotenciario del rey de Piamonte-Cerdeña Carlos Manuel IV. Sus páginas revelan al lector un carácter paradójico, pues se trata de un ensayo ficcional basado en un complejo entramado de voces y perspectivas narrativas resultado del cruce de diversas presencias autoriales; esta densa estructura textual contrasta, en cambio, con el mensaje monocorde que el mismo subtítulo de la obra introduce y que no es otro que el siguiente: la única respuesta satisfactoria a los grandes interrogantes existenciales consiste en ser consciente de la intervención continua de la Providencia a lo largo de la historia humana. Concretamente, en la velada que concluye esta obra, los interlocutores se centran en definir los conceptos de "profeta"y de "iluminado"a partir de una argumentación contrastiva entre ambos, cuyo fundamento lo constituye la relación que la Providencia establece con estas figuras humanas.

\footnotetext{
3 Salvo para las citas sacadas de Du Pape y de Lettres d'un royaliste savoyen à ses compatriotes, los demás textos de Joseph de Maistre que se incluyen en este artículo pertenecen a Euvres complètes de Joseph de Maistre, contenant ceuvres posthumes et toute sa correspondance inédite, publicadas por Vitte et Perrussel en Lyon entre 1884 y 1886 (reimpresas en fac-simil por Slatkine Reprints en 1979). A día de hoy se la considera la edición de referencia, como informa Pierre Glaudes al comentar la bibliografía empleada en su edición crítica Joseph de Maistre. Euvres (2007).
} 
El senador describe en su discurso cómo el profeta conoce por revelación al ser él mismo receptivo a los "signos divinos" que le son mostrados, a diferencia del iluminado tal y como lo representan las figuras que ejemplifican en el texto esta última condición; en contraste con la experiencia del profeta, el acto cognitivo del iluminado no deriva especialmente de la voluntad transcendente sino que es voluntarista motu propio, en cuanto que, según los argumentos posteriores que aporta el conde, en el proceso del conocimiento iluminista "il dépend de l'homme de désir4 de s'élever en grade jusqu'aux connaissances sublimes" (De Maistre,1884: 248). Este voluntarismo existencial queda gráficamente expuesto en las palabras del Conde mediante un símil no exento de sarcasmo, combinación poética habitual de la retórica maistriniana:

J'irai cependant mon train, messieurs, comme si le Tout-Puissant avait réussi, et tandis que les pieux disciples de Saint-Martin, dirigés, suivant la doctrine de leur maître, par les véritables principes, entreprennent de traverser les flots à la nage, je dormirai en paix dans cette barque qui cingle heureusement à travers les écueils et les tempêtes depuis mille huit neuf ans (De Maistre, 1884: 251).

A lo largo de su extensa intervención, este último personaje describe críticamente diversas manifestaciones del iluminismo o "Christianisme trascendental”, haciéndose eco de la denominación que emplearon algunos de sus adeptos. Así, el conde analiza el iluminismo masón, el teosofismo de Louis-Claude de Saint-Martin5 o ciertas corrientes derivadas del luteranismo para concluir que el conocimiento espiritual que dicen alcanzar se sitúa al margen de la voluntad divina:

Cette doctrine est un mélange de platonisme, d'origénianisme et de philosophie hermétique, sur une base chrétienne. Les connaissances surnaturelles sont le grand but de leurs travaux et de leurs espérances, ils ne doutent point qu'il ne soit possible à l'homme de se mettre

\footnotetext{
4 Como el lector de este trabajo podrá comprobar, las citas originales maistrinianas incluyen habitualmente términos en cursiva que hemos respetado al representar la intención del saboyano de que el lector fuera consciente de los pasajes o las expresiones que quería enfatizar. En este caso, quiere subrayar el empleo en su discurso de la expresión del mismo Louis-Claude Saint-Martin y que da título a su obra L'homme de désir (1790); con ella este pensador iluminista describe a la humanidad que aspira a volver a integrarse con Dios recuperando el estado anterior al pecado original.

5 El juicio anterior revela la evolución del pensamiento de Maistre quien, antes de su exilio en Lausana, formó parte de diferentes logias masónicas y llegó a tener amplio conocimiento de diferentes doctrinas esotéricas e iluministas. En aquella época leyó con atención las obras de Louis Saint-Martin y de estas lecturas pudieron surgir los embriones de temas capitales en el pensamiento del saboyano. No obstante, esta deuda intelectual queda matizada en las reflexiones expuestas en Les Soirées, a las que se unen las críticas a la posición de Saint-Martín sobre la jerarquía eclesiástica católica (vid. Glaudes, 2007: 1280).
} 
en communication avec le monde spirituel, d'avoir un commerce avec les esprits et de découvrir ainsi les plus rares mystères (De Maistre, 1884: 248).

De este modo, en los argumentos del senador y del conde, el profetismo, en oposición al iluminismo, se presenta como una experiencia cognitiva superior por ser precisamente fruto de una revelación de origen divino, ausente en cambio de la experiencia iluminista:

Pourquoi voulez-vous qu'il n'en soit pas de même aujourd'hui ? L'univers est dans l'attente. Comment mépriserions-nous cette grande persuasion ? Et de quel droit condamnerions-nous les hommes qui, avertis par ces signes divins, se livrent à des saintes recherches ? (De Maistre, 1884: 237).

Por otra parte, en esta misma velada la voz del senador introduce ante sus interlocutores una opinión derivada de la consideración anterior, por la que la relación especial del profeta con la Providencia le permite experimentar una vivencia única de la temporalidad que consiste en liberarse del transcurrir cronológico. El profeta adquiere en este proceso un conocimiento panóptico del transcurrir temporal que resulta inaccesible a otros mortales. Tal es el caso para el senador del rey-profeta David quien "présent à l'avenir", en el Salmo XXI se representa a sí mismo en su condición actual de "juste persécuté" bajo la imagen premonitoria de otro "justo perseguido" posterior, el Cristo doliente de la Pasión:

Le prophète, jouissant du privilège de sortir du temps, ses idées n'étant plus distribuées dans la durée, se touchent en vertu de la simple analogie et se confondent, ce qui répand nécessairement une grande confusion dans ses discours [...] C'est encore ainsi que David, conduit par ses propres souffrances à méditer sur le juste persécuté, surtout à coup du temps et s'écrie, présent à l'avenir: Ils ont percé mes mains et mes pieds; ils ont compté mes os ; ils se sont partagé mes habits : ils ont jeté le sort sur mon vêtement ${ }^{6}$ [Ps, XXI, 17-19] (De Maistre, 1884: 234).

En esta cita, la enunciación profética del presente vaticina el futuro en una dinámica de fusión representada analógicamente por la imagen crística que el profeta da de sí mismo en un acto anunciador. Los profetas, representados por el rey David, se convierten en visionarios porque su conocimiento se sitúa más allá del tiempo y del espacio de la circunstancia y de la aprehensión inmediatas, tanto propias como ajenas. "Pourquoi blâmeriez-vous les hommes qui s'élancent dans cet avenir majestueux et se glorifient de le deviner ?”, concluye el senador (De Maistre, 1886: 233).

${ }^{6}$ La cursiva con la que Joseph de Maistre transcribe la cita bíblica de los Salmos era habitual en el uso tipográfico de su tiempo destinado al discurso directo. 
Profetizar, en consecuencia, tal y como queda expresado en esta velada de Les Soirées de Saint-Pétersbourg. Entretiens sur le gouvernement temporel de la Providence equivale a comprender en extensión y profundidad la certeza de lo anunciado por los signos divinos, incluso fuera de toda lógica racional y diacrónica. Ahora bien, estos caracteres del hacer profético que el pensador detectó en otros, fueron reconocidos por determinados lectores en la propia obra del saboyano, tal y como ejemplifican algunos de los testimonios que pasamos a considerar en la siguiente etapa de nuestra investigación.

\section{Los lectores consideran el profetismo de Joseph de Maistre.}

Entre el conjunto de testimonios que se han ido sucediendo a lo largo de más de dos siglos, hemos escogido centrarnos en aquellos que, relativamente cercanos cronológicamente al pensador saboyano, han contado con menor espacio de comentario o con ninguno en los en estudios dedicados a su relación con otros escritores decimonónicos. Nos referimos al del crítico literario y novelista Charles-Augustin Sainte-Beuve y al de un lector anónimo de Considérations sur la France -un militar ruso, quien se presenta epistolarmente con las iniciales M.O-.

Este último testimonio, fechado en la Nochebuena de 1814, es una carta7 que un tal M. O., general del ejército del "emperador de todas las Rusias", remitió al propio De Maistre. En ella le expresa el entusiasmo que le han producido estas páginas -"cette lecture a produit en moi une sensation si vive"- a la vez que, entre otros comentarios, reconoce el carácter profético de las mismas:

La partie prophétique de l'ouvrage m'a également frappé. Voilà ce que c'est que d'étudier que d'une manière spéculative en Dieu. Ce qui n'est pour la raison qu'une conséquence obscure, devient révélation. Tout se comprend, tout s'explique quand on se remonte à la grande cause. Tout se devine, quand on se base sur elle (De Maistre, 1884 : LI).

Las frases anteriores constituyen, a nuestro entender, una descripción certera del conocimiento profético que esta carta define como "étudier

7 Este documento, de gran pertinencia a nuestro entender, no suele aparecer en la mayoría de las ediciones de Considérations sur la France que hemos podido consultar. Se encuentra por vez primera en la de 1841, realizada por M. l'Abbé Migne, y también se incluye en las Obras completas de 1884-1886, fuente de las citas que incluye este artículo. Ediciones modernas, como la publicada por Éditions Complexe en 1988 y prologada por Pierre Manent la incluye, pero no comenta nada sobre el contenido de esta carta dirigida a Joseph de Maistre. Otras, en cambio, no lo la presentan, como es el caso de la edición crítica de Pierre Glaudes (2007), a la que ya se ha aludido. Por otra parte, a nuestro juicio, es probable que el texto de Considérations sur la France al que alude el general ruso sea el de la edición de 1814, revisada por De Maistre y publicada ese mismo año en París. Nuestra suposición se apoya en la coincidencia entre el año de publicación y la fecha de la carta, 24 de diciembre de 1814 . 
d'une manière spéculative en Dieu". Esto es, el profeta investiga la realidad y la medita desde una perspectiva transcendente -"spéculer en Dieu"-, de la que sus juicios -“considérations"- son deudores. El resultado de esta íntima relación con la potencia transcendente es que el profeta, como médium cognitivo - "los profetas son portadores de una nueva revelación, de un encargo divino especial" (Weber, 2014 [1922]: 619)-, comprende certeramente lo ocurrido y aclara así lo que resultaba oscuro para la razón. Interpretar una información divina y transmitirla son acciones esenciales del ejercicio profético:

De acuerdo con las fuentes más antiguas, el $\pi \rho \circ$ poítn es el que interpreta las voces inconexas de la Pitia en el oráculo de Delfos. Lo que Zeus hace saber a Apolo, y que articula de forma lógica y poética la revelación del dios. Por consiguiente, el profeta es el que comunica o proclama el mensaje de la divinidad a los hombres. Sin embargo, como este mensaje se refería muchas veces al

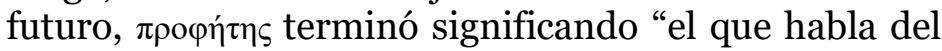
futuro", el que predice. Así ha llegado también hasta nosotros (Sicre, 2012: 67).

En este sentido, la cita del lector ruso extraída de la misiva reconoce que las palabras de Joseph de Maistre sobre la Revolución francesa transmiten e interpretan para sus lectores un mensaje que demuestra la intervención de la Providencia sobre este acontecimiento histórico:

L'époque de la révolution française est une grande époque, c'est l'âge de l'homme et de la raison. La fin est aussi digne de remarque : c'est la main de Dieu et le siècle de la foi. Du fond de cette immense catastrophe, je vois sortir une leçon sublime aux peuples et aux rois. C'est un exemple donné pour ne pas être imité (De Maistre, 1884: LI).

Considérations sur la France se ofrece, por tanto, para este generallector de 1814, como un texto en parte profético por su condición de texto revelado en el sentido pleno del término, esto es, comunicador de una perspectiva transcendente cuya procedencia es "la grande cause" que la inspira y que da sentido a la existencia humana en todas sus dimensiones, carácter que comparte con los demás mensajes proféticos:

Le prophétisme atteste ainsi qu'une révélation reste la source vivante d'un comportement religieux, qu'elle ne saurait être définie une fois pour toutes dans le message originel, qu'elle participe du temps de l'histoire et qu'elle continue d'animer l'expérience humaine en général ainsi que l'expérience religieuse en particulier (Freund, 1990: 62).

En el caso de Charles Augustin Sainte-Beuve, su interés por el autor nació en 1826 y, tras dedicarle un amplio artículo aparecido en Revue des 
Deux Mondes en el verano de 1843, también hará que Joseph de Maistre sea el protagonista de un amplio capítulo publicado en el volumen II de sus Portraits littéraires, aparecido en 1841; dicha semblanza fue fruto de un exhaustivo trabajo de recopilación de datos para el que la ayuda de amigos y familiares del ensayista resultó clave (De Maistre, 2007: 1278). No obstante, no será esta la última vez en que el estudioso se interese por el trabajo de Joseph de Maistre. Más tarde, volverá a evocar su figura y pensamiento en el tomo IV de Causeries du Lundi (1851-1862) y en el capítulo XIV del libro III de Port Royal (1840-1859).

La lectura completa del capítulo de Portraits littéraires pone en evidencia que la pluma de Sainte-Beuve convierte la figura del profeta en un leit-motiv recurrente a lo largo de su amplia evocación de la vida y obra del ensayista; incluso esta misma figura funcionará como mediadora analógica para describirlo físicamente en un determinado momento del capítulo:

À le voir avec la tête haute toujours découverte, ses beaux cheveux blancs et son verbe ardent enflammé, il avait l'air d'un prophète : "C'est comme notre Etna, disait un jour un seigneur sicilien qui sortait de causer avec lui, il a la neige sur la tête et le feu dans la bouche. Pare il notro Etna: la neve in testa e dil fuoco in bocca (Sainte-Beuve, 1862: 468).

Ya en las primeras líneas del mismo el crítico francés había resaltado, en su opinión, el carácter profético del pensador y de su mensaje:

Nous l'étudierons d'abord en lui-même, nous y reconnaîtrons et nous y suivrons de près l'homme antique, immuable, à certains égards prophétique, le grand homme de bien qui a senti et proclamé avec une incomparable énergie ce qui allait si fort manquer aux sociétés modernes en cette crise de régénération universelle (Sainte-Beuve, $1862: 392$ ).

Como otros ya habían hecho anteriormente ${ }^{8}$, las palabras del crítico francés reconocen en las obras de Joseph de Maistre un impulso profético

\footnotetext{
${ }^{8}$ Aunque de sobra comentadas por la crítica, no podemos dejar de mencionar las alusiones continuas al autor por parte de Jules Barbey d'Aurevilly a lo largo de su carrera literaria. A él le dedicó el novelista, entre otros escritos, el primer capítulo de Les prophètes du passé (1851), en el que se refiere al profetismo político de nuestro autor:"Tout ce qui sait lire n'a pu oublier l'admirable chapitre IX, cette suite d'éclairs, dans Considérations sur la France, intitulé "Comment se fait une contre-révolution". Les grandeurs et les folies de l'homme qui avait, en ressuscitant la monarchie, comme écrit avec son épée, sous la dictée du prophétisme politique, qui l'avait proclamé nécessaire et inévitable, ne modifièrent qu'à peine l'histoire qu'il avait tracée de si loin de la Restauration future.". (1851: 28). Tampoco queremos omitir la admiración baudeleriana por el ensayista, al que el poeta reconoció en $\mathrm{Fu}$ sées como su "maitre à penser" junto con Edgard Allan Poe a la vez que distinguía su hacer profético en la definición que dio del saboyano: "le grand génie de notre temps. Un voyant !". (Baudelaire, 2016: 198). Un panorama completo de esta influencia y de su consideración bajo la perspectiva profética se refleja, especialmente, en el pensamiento político de
} 
en su voluntad de presentar y declarar un mensaje que la mayoría de sus coetáneos no apreciaron al estar imbuidos, según Sainte-Beuve, del espíritu positivista dominante en la sociedad del momento. De Maistre se erige, pues, en esta cita, como un Jeremías que clama en el desierto de su época sin haber conmovido ni convencido a unos contemporáneos voluntariamente alejados de su visión de la existencia. En este sentido, parte del mensaje de Considérations sur la France vendría a renovar, a partir del comentario de Sainte-Beuve, el "profetismo de la maldición", término que el estudioso Pierre Gibert (2012: 45) aplica a una parte del profetismo bíblico, en el que la misión del profeta sería "rappeler au peuple ses fautes tant envers Yhwh qu'envers autrui, et lui signifier le châtiment divin qu'appellent de telles fautes". En el caso del crítico decimonónico, los juicios y reflexiones que las páginas de Considérations sur la France presentan sobre el cataclismo revolucionario permiten que "la voix de Dieu s'élance toute majestueuse du milieu des orages du Sinaï: en quoi la nation française est coupable" (Sainte-Beuve, 1862: 424); culpabilidad y alusión al discurso de Dios que asimila, en la mente del lector del texto maistriniano, el destino de la Francia inmersa en la revolución con la infidelidad del pueblo israelita a los designios de la Providencia tal y como se narra en los primeros libros del texto sagrado.

Por otra parte, en la posterior descripción que Sainte-Beuve realiza de los distintos capítulos del ensayo, resaltará que los análisis del saboyano acabaron funcionando como predicciones que a veces llegaron a cumplirse -"En 1796 M. de Maistre prédisait sans marchander une Restauration"-, dotándolas además de una percepción transcendente, lo que las singularizaría en su tiempo:

Sous la question, toute civile et politique en apparence qu'elle [la révolution française] était devenue, il découvre le caractère religieux, le sens théologique si vérifié par ce qui s'est produit à nos yeux depuis quarante ans, et lors de la grande réaction de 1800 , et dans ce mouvement actuel, persistant et encore inépuisé des esprits. Il ne craint pas de poser le grand dilemme dans toute sa rigueur: "Si la Providence efface, c'est sans doute pour écrire" (Sainte-Beuve, 1862: 427).

Así pues, Considérations sur la France se presenta a los ojos del Sainte-Beuve lector como un escrito sorprendente -incluso en sus vaticinios erróneos, no omitidos en la semblanza-, que con el tiempo no ha hecho más que confirmar su "valentía profética" (Sainte-Beuve, 1862: 422), además de ser la piedra angular del edificio ensayístico que concluyó con la publicación

la primera mitad del siglo XIX, tal y como describe la investigadora Carolina Armenteros en la segunda parte de su monografía L'idée française de l'histoire. Joseph de Maistre et sa postérité (1794-1854) (2018). 
póstuma de Les Soirées de Saint-Pétersbourg. Entretiens sur le gouvernement temporel de la Providence.

\section{Las intuiciones proféticas: consideraciones sobre algunos va- ticinios maistrinianos.}

Publiées en avril 1797, les Considérations ne suscitèrent en effet un vaste élan d'admiration qu'en 1814, année de leur "grande explosion", selon la formule de l'auteur luimême [...] Il fallut attendre le retour des Bourbons pour qu'une réédition opportune fût remarquée, le public saluant lors les intuitions prophétiques de l'ouvrage, dont le chapitre IX parut anticiper, avec une exactitude troublante, sur les événements de cette époque (De Maistre, 2007: 177)

En efecto, las páginas publicadas en 1797 fueron para parte de la opinión pública francesa no sólo la carta de presentación en sociedad del jurista sino también una prueba de su capacidad de videncia en cuanto que habían revelado e interpretado los designios divinos para esta nación. De hecho, el texto, en algunos momentos de su discurrir, se configura a los ojos del lector como una amplia respuesta esclarecedora, ofrecida por su narrador a un interlocutor anónimo en quien se concreta el desconcierto generalizado de muchos coetáneos ante la convulsión provocada por la Revolución francesa:

Je n'y comprends rien, c'est le grand mot du jour. Ce mot est très sensé, s'il nous ramène à la cause première qui donne dans ce moment un si grand spectacle aux hommes : c'est une sottise, s'il n'exprime qu'un dépit ou un abattement stérile. [...] Comment donc (s'écrie-t-on de tous côtés) ? Les hommes les plus coupables de l'univers triomphent de l'univers ? Un régicide affreux a tout le succès que pouvaient attendre ceux qui l'ont commis ! La monarchie est engourdie dans toute l'Europe ! [...] les premiers hommes d'État se trompent invariablement! Les plus grands généraux sont humiliés! etc. (De Maistre, $1884: 3$ ).

Desde la perspectiva providencialista del autor de estas líneas, la impotencia cognitiva, expresada en la primera frase del fragmento y en las siguientes preguntas, se transmuta en conocimiento y se convierte, desde su posición de vidente, en clave comprensiva: "Mais jamais l'ordre n'est plus visible, jamais la Providence n'est plus palpable que lorsque l'action supérieure se substitue à celle de l'homme et agit toute seule. C'est ce que nous voyons dans ce moment" (De Maistre, 1884: 4). Ese "nous voyons" contiene un enorme potencial interpretativo para el lector que pretende entender los argumentos vertidos en el libro. Para el ensayista, comprender correctamente con una perspectiva providencialista es ver; comprender de otro modo es estar ciego. Los temas de la ceguera, en cuanto que comprensión 
errónea, y el tema de la visión, en cuanto que comprensión correcta, vertebran la argumentación de la obra de 1797. José Luis Sicre, en su monografía sobre el profetismo bíblico, reconoce la diferencia entre la visión del profeta y la del no iniciado a partir de la dinámica de la visión superficial y la visión profunda y certera, propia del conocimiento profético.

El profeta percibe lo mismo que puede ver cualquier israelita: una rama de almendro, una olla de fuego, dos cestos de higos. A partir de un dato inmediato llega a una percepción más profunda de la realidad. Lo que tiene delante da pie para descubrir algo nuevo, invisible a los ojos ordinarios, para captar la realidad de forma distinta o profundizar en la acción de Dios (Sicre, 2012: 82).

Conocer proféticamente supone una invitación a ver y comprender a contrapelo, a descodificar continuamente la evidencia empírica y sus correlatos reflexivos:

Maistre concebía la razón divina como una actividad transcendente y oculta, por tanto a la visión humana. No puede deducirse de ningún conocimiento obtenido por simples medios humanos; se pueden otorgar vislumbres de ella a los que han penetrado en el mundo revelado de Dios, y pueden saber así de una naturaleza y una historia determinadas por la divina providencia, aunque no puedan entender sus formas y propósitos. Se sienten seguros porque tienen fe. No se plantean dudas porque tienen sabiduría suficiente para comprender que es una necedad aplicar categorías humanas al poder divino. No buscan en especial teorías generales que lo expliquen todo, Pues no hay nada más mortífero para la verdadera sabiduría que los principios generales establecidos científicamente (Berlin, 1992: 133).

Según $\mathrm{M}^{\mathrm{a}}$ Luisa Guerrero, las páginas de Joseph de Maistre insisten en apelar a "un lector activo que acceda, a través de este ejercicio visionario que él le propone, al revés de la trama del gran tapiz que ha tejido en su acontecer la Revolución francesa" (De Maistre, 2015: 13). De este modo, por ejemplo, se puede acceder a la visión correcta de los protagonistas de la etapa más convulsa del acontecimiento, el Terror jacobino con Maximilien Robespierre a la cabeza. Los argumentos providencialistas expuestos en Considérations sur la France perciben a esos hombres como instrumentos adyuvantes de Dios y nunca como individuos libres cuya voluntad fue cambiar voluntariamente el curso de la historia de su país, "Qu'on y réflechisse, on verra que le mouvement révolutionnaire une fois établi, la France et la monarchie ne pouvaient être sauvées que par le jacobinisme" (De Maistre, 1884: 13). Por esta razón, todo lo "que los tiranos de Francia" decretaron fue 
lo mejor, incluido el ejercicio continuo de la guerra dentro y fuera de las fronteras de la República. 9

La conversión del saboyano a esta visión providencialista propia de la hermenéutica profética puede situarse después de 1793, año en el que el ejército coaligado austro-piamontés fracasó en su intento de reconquistar Saboya a las tropas de la Convención. La idea concebida por De Maistre sobre una etapa revolucionaria que sería pasajera se esfumó entonces, tal y como lo atestiguan su correspondencia y algunas alusiones contenidas en Lettres d'un royaliste saboyen à ses compatriotes, publicadas anónimamente este mismo año. El senador liberal conservador de antaño se transmuta gracias a una "iluminación", según sus propias palabras ${ }^{10}$ en un vidente que aplica un filtro providencialista a los acontecimientos revolucionarios y a sus consecuencias en toda Europa. De este modo, "Les Comices tant désirés et célébrés d'avance sont le châtiment d'un siècle de crimes et de folies ; c'est un jugement de la Providence qui fera trembler l'univers, et tel que l'historien n'en offre pas d'exemple" (De Maistre, $1872: 49$ ). Como ocurrirá cuatro años después en Considérations sur la France, las palabras del ensayista adquieren ya en este epistolario la forma de oráculos en los que vaticina para la Francia revolucionaria un futuro apocalíptico:

La nature qui balance tout avec sa sagesse, en donnant un caractère impétueux et terrible t'a fait trois présents inestimables, qui ne lui laissent rien de dangereux : ton Roi, ton culte et tes préjugés. Eh bien ! Ces hommes que tu appelles tes Représentants, te priveront de tout cela. Ils seront plus forts que toi, plus forts que la nature : en peu de mois, ils feront de toi un autre peuple ; ils corrompront la corruption même, et l'histoire sera crue à peine lorsqu'elle parlera de toi. Semblables à ces reptiles impurs dont toute la force est dans le venin, ils ne posséderont que l'art de faire le mal (De Maistre, $1872: 50$ ).

No obstante, este discurso profético de destrucción, cuyos entresijos y sentido último explicará más tarde desde la perspectiva providencialista en Considérations sur la France, se completará además en este último texto con otra profecía centrada en un futuro esperanzador, tal y como explicita la conclusión del renombrado capítulo IX de este ensayo "Comment se fera

9 No es otro el argumento central del capítulo III del ensayo "De la destruction violente de l'espèce humaine" en el que el saboyano realiza un encendido elogio del papel de las guerras en la historia de la humanidad. Sus comentarios repasan la estrecha relación entre los conflictos bélicos más importantes y la grandes épocas históricas; a partir de esta tarea el pensador invita a "presentir los planes de la Providencia" en todas estas convulsiones violentas. Los argumentos y ejemplos históricos se agolpan en su pluma para concluir con la interrelación ante aludida.

${ }^{10}$ Es el término que él mismo empleó al referirse a este cambio de percepción del acontecimiento histórico y que aparece en Les Carnets du Comte Joseph de Maistre, publiés par le comte Xavier de Maistre. Livre journal 179o-1812, (1927) Lyon, Vitte, 1923, p.217, citado por Pierre Glaudes, (2007: 185). 
la contre-révolution, si elle arrive ?”. El contenido del mismo se detiene en describir la restauración de una nueva Francia cristiana de esencia prerrevolucionaria, cuya piedra angular será un nuevo rey "cristianísimo":

Il n'a pas besoin des légions étrangères ; il n'a pas besoin de la coalition; et comme il a maintenu l'intégralité de la France, malgré les conseils et la force de tant de princes, qui sont devant ses yeux comme s'ils n'étaient pas, quand le moment sera venu, il rétablira la monarchie française malgré ses ennemis, il chassera ces insectes bruyants pulveris exigui jactu: le Roi viendra, verra et vaincra. Alors, on s'étonne de la profonde nullité de ces hommes qui paraissent si puissants. Aujourd'hui, il appartient aux sages de prévenir ce jugement, et d'être sûrs, avant que l'expérience l'ait prouvé, que les dominateurs de la France ne possèdent qu'un pouvoir factice et passager, dont l'excès même prouve le néant, qu'ils n'ont été ni plantés ni semés ; que leur tronc n'a point jeté des racines dans la terre, et qu'un souffle les emportera comme la paille (Isaïe, XL, 24) ${ }^{11}$ (De Maistre, $1884: 119)$.

Este fragmento final del capítulo se presenta como el sumario de la gran profecía cuyo significado funciona en dos planos de comprensión: no sólo constata en ella la incompetencia de los gobernantes republicanos y la inutilidad de la guerra contrarrevolucionaria que se les opone sino que, además, propone al lector una suerte de autorretrato en el que De Maistre se representa como uno de esos sabios a quienes corresponde predecir y pronunciarse con certeza antes de que la experiencia demuestre el poder "facticio y pasajero" de los dominadores de Francia.

Su pluma traza en este contexto los rasgos esenciales de la figura y función proféticas, tal y como quedaron enunciados en páginas precedentes de esta investigación, dichos caracteres, recordemos, se concentran en la idea de un conocimiento revelado de los hechos que se anticipa a su acontecer empírico. La confirmación de este autorretrato del autor como profeta reside en la cita del libro de Isaías que concluye el reverso de la profecía del saboyano, cuyo anverso es el advenimiento de una Francia monárquica y cristiana. Las palabras del profeta bíblico invitan de nuevo al lector a realizar una doble interpretación de las mismas; en efecto, no sólo proclaman la futilidad del poder terrenal por su falsedad y condición pasajera sino que relaciona la profecía incluida en el libro de 1797 con la voz ancestral de Isaías, cuyas palabras se convierten en eco del doble vaticinio maistriniano:

\footnotetext{
${ }^{11}$ Hemos reproducido la cita anterior como ejemplo de mezcla de la cursiva "expresiva", propia del autor ya comentada y la cursiva aplicada en la tipografía de la época a citaciones literales, en este caso del Libro de Isaías, lo que sirve también para ilustrar la concomitancia de los argumentos maistrinianos con los textos proféticos, aspecto en el que pronto se centrarán estas líneas.
} 
la caída de la Francia republicana y la llegada de un nuevo rey cristiano portador de la esencia de la Francia del Antiguo Régimen.

Por otra parte, las concomitancias de Considérations sur la France con otros libros proféticos pueden extenderse a una enunciación y un modo de composición textual que le harían seguir en gran medida los patrones de una poética bíblica, tal y como la estudia, por ejemplo, el investigador Julio Trebolle en Imagen y palabra de un silencio: la Biblia en su mundo (2000). En efecto, en la poesía bíblica, "básicamente oracular", "lo escrito con imaginación ha de ser leído e interpretado con igual imaginación. No basta con leer los textos, es preciso verlos, vislumbrar tras la metáfora la imagen plástica que la inspira (Trebolle, 2000: 21).

Esta es la razón por la que, a nuestro entender, Joseph de Maistre, desde Considerations sur la France y, especialmente en este su primer ensayo, ofrece a sus contemporáneos no sólo un contenido de mensaje profético, sobre el que volveremos a interesarnos, sino también una poética profética que se inaugura con la impactante analogía inicial de este texto: "Nous sommes tous attachés au trône de l'Être Suprême par une chaîne souple, qui nous retient et nous asservit" $(15)^{12}$; dicha imagen bien podría funcionar a modo de epifanía visual que el narrador aplica a la historia de Francia, como la continuación del ensayo irá demostrando. Los vaticinios derivados de dicha visión se suceden en el texto y constituyen los ejemplos de la singular subordinación humana a la voluntad divina, que no podrían encontrar mejor expresión poética que el oximorón "chaîne souple": en él se visualiza la indisoluble convivencia del movimiento humano con el dominio vigilante del Ser Supremo que lo limita inexorablemente. Como establece Pierre Glaudes, la retórica hiperbólica y sublime del autor encuentra su sentido último en una metafísica:

Pour subjuguer le lecteur par sa force de conviction, la rhétorique maistrinienne le fait passer des énigmes qui scandalisent son ignorance à l'éclat d'une vérité aveuglante, ne lui laissant d'autre choix que de se rendre à son pouvoir [...] Car la logique consolante qui intègre dans un plan providentiel le conflit du "mauvais principe" et de son "divin antagoniste" est une anticipation de ce moment solennel où, dans le définitif apaisement

\footnotetext{
${ }^{12}$ En efecto, el repertorio de analogías maistrinianas ha llamado la atención de estudiosos como Pierre Labarthe, quien le dedica un capítulo en Baudelaire et la tradition de l'allégorie denominado "Violence et allégorie: Baudelaire lecteur de Joseph de Maistre". A este respecto son imprescindibles los comentarios sobre el estilo del saboyano que desarrolla de Antoine Compagnon en Les antimodernes. De Joseph de Maistre à Roland Barthes (2005: 140-149), considerando que "S'il a procédé en anthropologue de la politique expérimentale en théologicien de la métapolitique " [...] De Maistre a d'abord été un styliste.
} 
des passions humaines, chacun pourra peut-être déchirer le voile nocturne dont il est enveloppé (De Maistre, 2007: 195).

Por otra parte, la inclusión de la fórmula oximorónica antes aludida, le sirve a De Maistre para renovar una imagen de la figura de Dios de amplia tradición bíblica, la de la divinidad entronizada, presente, entre otras visiones, en la que describe el profeta Ezquiel durante su exilio en Babilonia:

Caí rostro a tierra, mientras la gloria de Yahvé penetró en la casa por la puerta de la fachada que da al Oriente [...] y oí que alguno me hablaba desde dentro de la casa y me decía: Hijo de hombre, éste es el lugar de mi trono, el escabel de las plantas de mis pies, donde habitaré para siempre en medio de los hijos de Israel (Ezequiel, 43, 57).

Junto a las precisiones anteriores sobre el uso del oxímoron, "figure centrale de la rhétorique maistrinienne" (Compagnon, 143), resulta de interés subrayar el empleo en el ensayo por parte del escritor de lo que vendría a ser un micro relato vaticinador que funcionaría como las narraciones denominadas "Visiones" en el Antiguo Testamento y que los profetas bíblicos suelen presentar ante un receptor individual o a un auditorio. Tal es el contenido argumentativo central del ya mencionado capítulo IX, "Comment se fera-t-elle la Révolution, si elle arrive ?”, donde la pluma del escritor convierte su creencia en el acontecimiento restaurador en un relato de ficción centrado en los primeros momentos del mismo; en esta parte del texto, la dominante narrativa del discurso se resuelve en la presentación de diferentes personajes, cronotopos y procesos actanciales que desarrollan la ensoñación ficcionalizada por el narrador:

Un courrier arrivé à Bordeaux, à Nantes, Lyon, etc., apporte la nouvelle que le Roi est reconnu à Paris, qu'une faction quelconque (qu'on nomme ou qu'on ne nomme pas) s'est emparée de l'autorité, et a déclaré qu'elle ne la possède qu'au nom du Roi : qu'on a dépêché un courrier au souverain, qui est attendu incessamment, et que de toutes parts on arbore la cocarde blanche. [...] Chaque officier qui ne jouit d'aucune considération, et qui le sent très bien, quoiqu'on en dise, voit tout aussi clairement que le premier qui criera vive le Roi ! sera un grand personnage [...] le soldat qui n'est pas électrisé par son officier, est encore plus découragé ; le lien de la discipline reçoit un coup inexplicable, ce coup magique qui le relâche subitement. L'un tourne les yeux vers le payeur royal qui s'avance; l'auteur profite de l'instant pour rejoindre sa famille : on ne sait ni commander ni obéir ; il n'y a plus d'ensemble.

C'est bien autre chose parmi les citadins : on va, on vient, on se heurte, on s'interroge : chacun redoute, celui 
dont il aurait besoin ; le doute consume les heures, et les minutes sont décisives [...] On attend ; mais le lendemain on reçoit l'avis qu'une telle ville de guerre a ouvert ses portes, raison de plus pour ne rien précipiter. Bientôt on apprend que la nouvelle était fausse ; mais deux autres villes qui l'ont crue vraie, ont donné l'exemple, en croyant le recevoir ; elles viennent de se soumettre, et déterminent la première, qui n'y songeait pas. Le gouverneur de cette place présente au Roi les clefs de $s a$ bonne ville de ... [...] À chaque minute le mouvement royaliste se renforce ; bientôt il devient irrésistible. vIVE LE ROI ! Répond l'hypocrite républicain, au comble de la terreur. Qu'importe ? Il n'y a qu'un cri - Et le Roi est sacré.

Citoyens ! Voyez comment se font les contre-révolutions (De Maistre, 1884: 115-117).

Sin embargo, el autor de estas líneas no será testigo del advenimiento del rey objeto de esta visión, en consonancia con la profecía del Gran monarca o del Divino soberano, que arraigó con fuerza en Europa desde el siglo XVI y se prolongará en Francia hasta finales del siglo XIX, adaptándose a las convulsiones políticas de este largo periodo ${ }^{13}$. Porque no será Louis XVIII quien responda al modelo de rey consagrado, representación en el imaginario maistriniano del monarca cristianísimo, como de hecho evocan algunas páginas del ensayo de 1797. Las relaciones del escritor con el antiguo Conde de Provenza fueron más bien difíciles a pesar de un primer contacto epistolar fluido que malentendidos sociales y desacuerdos ideológicos fueron dinamitando poco a poco. El primer paso en ese desacuerdo fue la promulgación en junio de 1814 de la Charte constitutionnelle, cuyo articulado otorgaba a la nación francesa algunos de los derechos presentes en la Declaration des Droits de l'Homme et du Citoyen, circunstancia que demostraba que Louis XVIII no iba a cumplir con el programa político vaticinado por el narrador visionario de Considérations sur la France. En efecto, la voluntad que se desprendía de los distintos artículos que componían esta

13 La visión del Divino soberano descrita por De Maistre es una contribución más en el conjunto de escritos sobre este tema que vieron la luz en vísperas y durante la Revolución y que se remontan al siglo XVI (Armogathe, 2012:169); de hecho, como ocurrió con el ensayo Considérations sur la France, algunos de ellos volverán a editarse durante la Restauración y se seguirán leyendo a lo largo del siglo:

Un nouveau courant prophétique se dessine, qui espère, dans

l'imminente survenue du Grand Monarque, la restauration de l'ordre déchu de la monarchie de droit divin et de la " religion du royaume "; il rejaillera avec force lors du renversement de la monarchie légitime des Bourbons de la branche aînée en 1830, puis lors des projets de restauration monarchique des années 1870 , au lendemain de la défaite et de la Commune (Boutry, 2012 : 223). 
Charte aspiraba a enlazar la monarquía no tanto con el Antiguo Régimen puro, espacio donde se encuadraba la profecía de Joseph de Maistre, sino con algunos de los principios políticos del pensamiento ilustrado, denominado en los escritos del ensayista philosophisme ${ }^{14}$. Con esta promulgación, el monarca restaurado en 1814 se desmarcó de la figura del rey que el pensador saboyano describió cuidadosamente en Considérations sur la France y cuya acción se inspiraba en la estrecha alianza entre Trono y del Altar:

C'est au nom du Dieu TRÈS-GRAND ET TRÈS-BON, à la suite des hommes qu'il aime et qu'il inspire, et sous l'influence de son pouvoir créateur, que vous reviendrez à votre ancienne constitution, et qu'un Roi vous donnera la seule chose que vous deviez désirer sagement : la liberté par le monarque. (De Maistre, 1884: 124).

La reacción de Joseph de Maistre a la decisión real no se hizo esperar: lejos de desdecirse de su mensaje profético reconociendo que su vaticinio no se había realizado por completo ${ }^{15}$-, decidió volver a imprimir, meses después de la primera edición, Essai sur le príncipe générateur des constitutions politiques et des autres institutions humaines, cuya tesis central, ya avanzada en el capítulo VIII de Considérations sur la France, establece el origen divino y la consiguiente perennidad de toda Constitución que se tome por válida, destinada por ello a permanecer "ès-cœurs des Français", contraponiéndola por esta razón a los textos constitucionales objeto de las deliberaciones humanas y contrarios, por tanto, a lo que había sido la hoja de ruta de la monarquía francesa hasta el cataclismo revolucionario.

Así pues, con Louis XVIII en el trono, De Maistre emprende su carrera diplomática en San Petersburgo al servicio de otro rey, Carlos Manuel IV de Saboya. La ciudad rusa será el marco en el que redactará los textos

14 En nuestro autor, la posible equivalencia entre el término philosophisme y el pensamiento ilustrado resulta matizada en cuanto que, cuando lo emplea, suele ser para oponerlo al cristianismo; así aparece en Considérations sur la France: "la génération présente est témoin de l'un des plus grands spectacles qui aient occupé l'œil humain: c'est le combat à outrance du christianisme et du philophisme. La lice est ouverte, les deux ennemis sont aux prises, et l'univers regarde" (De Maistre, 1884: 62). Dicho lo anterior, la equivalencia de todos modos llega a producirse en los escritos posteriores del autor, ya que en ellos el ensayista establece que las distintas propuestas del pensamiento ilustrado coinciden en su común rechazo a los dogmas del catolicismo, tal y como desarrolló posteriormente en los apartados XLIII y XLIV de Essai sur le príncipe générateur des constitutions politiques (1814) (De Maistre, 1884: 283-284).

${ }^{15} \mathrm{Si}$ bien es cierto que la Restauración en la figura de Louis XVIII trajo un oscurecimiento parcial de la ortodoxia republicana, fue sin discusión su sucesor Charles X, durante su breve reinado (1824-1830), quien mostró a las claras una voluntad de anular el legado de 1789 con su proyecto de vuelta en algunos aspectos a la Monarquía prerrevolucionaria, finalmente fracasado. En este sentido, el interrogante podría plantearse: ¿Para Joseph de Maistre, Charles X hubiera encarnado, al menos por su concepción del poder real y sus acciones concretas (por ejemplo, su decisión de consagrarse en 1825), al rey cristianísimo vaticinado en sus escritos? Pregunta que quedó sin respuesta por parte del saboyano, muerto en 1821, y que, por tanto, sólo puede considerarse desde la especulación de los investigadores. 
más importantes de su última etapa, Du Pape (1819) y Les Soirées de Saint Pétersbourg ou Entretiens sur le gouvernement temporel de la Providence, nuevas prospecciones dentro del gran núcleo temático del ensayista, la acción de la Providencia en todas las vertientes de la historia humana. El autor insistirá, pues, en profundizar en el objeto de su revelación profética que ya antaño aplicara a la Revolución francesa.

El texto de 1819 plantea ante los lectores de nuevo la visión de una Francia y de una Europa que, bajo la autoridad del Sumo Pontífice, concretarían la visión de una Jerusalén celeste que estas páginas van describiendo. No hay otro camino para acceder a la utopía regresiva en la que nuestro autor enmarca el futuro del continente. El vaticinio central de Du Pape reitera la estrecha conexión entre la esfera trascendente y su realización sociopolítica, la monarquía de derecho divino, contemplada en este ensayo a la luz de la figura papal que debe guiarla y corregirla cuando se desvíe del proyecto supremo como, de hecho, ya ha sucedido en algunos momentos de la historia: "Toute nation européenne soustraite à l'influence du Saint-Siège, sera portée invinciblement vers la servitude ou vers la révolte. Le juste équilibre qui distingue la monarchie européenne ne peut être que l'effet de la cause supérieure que j'indique" (De Maistre, 1872: 299). Apoyándose en una larga descripción de estos momentos históricos, el saboyano expone:

La barbarie des guerres interminables ayant effacé tous les principes, réduit la souveraineté d'Europe à un certain état de fluctuation qu'on n'a jamais vu, et crée des déserts de toutes parts, il était avantageux qu'une puissance supérieure eût une certaine influence sur cette souveraineté[...] Le principe très vrai que la souveraineté vient de Dieu renforçait d'ailleurs ces idées antiques, et se forma une opinion à peu près universelle, qu'on attribuait aux papes une certaine compétence sur les questions de la souveraineté. Cette idée était très sage et valait mieux que tous nos sophismes (De Maistre, 1872: 204).

Invocando estos "sabios" principios, que él aplica ocasionalmente a la vida política europea, la vocación profética de De Maistre ofrece al lector en el capítulo XII del Libro II una nueva visión donde describe el resurgimiento del poder supremo papal en el seno de esa Francia ensoñada. El narrador de este nuevo micro relato de ficción, en nombre de unos Estados Generales operativos de nuevo, invoca al Papa Pío VII su intervención para frenar los abusos de un "souverain qui nous gouverne, très Saint-Père, et ne règne que pour nous faire perdre" (De Maistre, 1872: 213), ¿Louis XVIII, acaso?, no puede evitar preguntarse el lector de estas líneas.

Ejemplo de ficción política, esta nueva visión maistriniana invoca la época en que Gregorio VII promulgó su Dictatus Papae (1075), en el que se proclama la supremacía del poder papal sobre los soberanos de este mundo, incluido el Emperador del momento, Enrique IV. Una vez más, el papado 
medieval alimenta las visiones del ensayista decimonónico quien, además, sólo concibe esa solución para contrarrestar la "fiebre constitucional" que se ha apoderado de Occidente:

Que nous sommes aveugles, en général ! Et, s'il est permis de le dire, que les princes en particulier sont trompés par les apparences ! On leur parle vaguement des excès de Grégoire VII et de la supériorité des temps modernes; mais comment le siècle des révoltes a-t-il le droit de se moquer de ceux des dispenses ? Le Pape ne délie plus du serment de fidélité, mais les peuples se délient eux-mêmes [...] Une fièvre constitutionnelle, on peut, je crois, s'exprimer ainsi, s'est emparée de toutes les têtes, et l'on ne sait encore ce qu'elle produira [...] Qu'est-ce que les souverains ont gagné à ces lumières tant vantées et tant dirigées contre eux ? J'aime mieux le Pape (De Maistre, 1872: 216).

La producción ensayística de Joseph de Maistre concluye con Les Soirées de Saint Pétersbourg, nueva declinación, por así decir, del núcleo teológico que alimenta las propuestas proféticas del pensador desde Considérations sur la France. En este caso, la aplicación política de la perspectiva providencialista, dominante o muy presente en anteriores escritos, deja paso a especulaciones sobre cuestiones de teología pura, como la reflexión ya comentada sobre la singularidad del conocimiento profético o acerca de dogmas católicos como el pecado original o la reversibilidad de los méritos. Aun así, sin un marco histórico que rechazar -la Revolución- o que promover por el anuncio de uno nuevo - un Divino Monarca para la Francia venidera-, las voces del senador y del conde evocan en la velada undécima la profecía mesiánica que Virgilio expuso en su Cuarta Bucólica para, acto seguido, afirmar la vocación profética del género humano y la posibilidad de cumplimiento de sus vaticinios:

Jamais un être et, à plus forte raison, jamais une classe entière d'êtres ne saurait manifester généralement et invariablement une inclination contraire à sa nature. Or, comme l'éternelle maladie de l'homme est de pénétrer l'avenir, c'est une preuve certaine qu'il a des droits sur cet avenir et qu'il a des moyens pour l'atteindre, au moins dans certaines circonstances (De Maistre, 1884: 233).

De nuevo el recurso a un garante del pasado como el poeta latino, le sirve al ensayista para establecer en la historia de la humanidad una sucesión de voces proféticas cuyos ecos, entre ellos los de los tres conversadores, se van relevando y proyectan sus visiones en el futuro. El senador habla de un "universo a la espera", escenario donde se situaría el vaticinio de la futura "gran unidad" hacia la que los hombres van avanzando y con cuya alusión el conde había cerrado la segunda velada: "Nous sommes douloureusement et 
justement broyés; mais si de miserables yeux tels que les miens sont dignes d'entrevoir les secrets divins, nous ne sommes broyés que pour être mêlés" (De Maistre, 1884: 127. De este modo, por mediación de sus alter-ego, el ensayista saboyano clausura en su último escrito sus consideraciones sobre el hecho profético que desde su inicio de la vida pública le ocuparon y preocuparon. Su última visión de fraternidad futura quiere ser amplia y transnacional, superando la decepción que sufrió ante el devenir de los acontecimientos históricos franceses.

\section{Conclusiones}

El recorrido comentado por diferentes escritos de Joseph de Maistre arroja una primera evidencia: el conjunto de sus ensayos puede comprenderse como una serie de acercamientos caleidoscópicos al principio existencial que ilustra la analogía primera de Considérations sur la France y por el cual un hombre libremente esclavo ocupa la posición central del sistema ideológico del ensayista. La "suave cadena" que une a la criatura con su creador convierte en designio necesario de la Providencia lo que el hombre cree que es acto libre o un acontecimiento azaroso. No es otro el marco en el que se desarrolla para De Maistre la acción humana, tanto la maligna como la excelsa, la cual, para el pensador, sólo puede derivar de la comunicación continua con Dios, convertida en oración, en profecía o en sacrificio redentor, tal y como se expone en las distintas conversaciones de Les Soirées de Saint-Pétersbourg, especialmente en la novena y en la décimo primera veladas.

Las páginas precedentes se han centrado en la segunda deriva de la comunicación entre Dios y el hombre con el fin de dar cuenta de los diversos enfoques que el profetismo como tema adquiere en las reflexiones del saboyano, así como los caracteres proféticos que se incluyen en su propia obra. A este respecto, podría realizarse un enfoque unitario de la misma si se la considera el resultado de un impulso profético que ya aparece en los primeros escritos públicos del autor y que no hizo más que seguir presente y dinamizar el resto de su producción, convirtiéndole, según Sainte-Beuve en un "prophète à contre-coeur comme Cassandre" (Sainte-Beuve, 1862: 449). Más allá de considerar el cumplimiento escrupuloso o aproximado de los vaticinios maistrinianos, circunstancia que tanto atrajo a sus contemporáneos, pensamos que el acercamiento actual a la proyección profética de estos escritos debe hacerse viéndola como la matriz que permitió dar sustancia y coherencia a un edificio ideológico. De hecho, los elementos que lo configuran son unos ensayos construidos a partir de una sucesión de oráculos y visiones que el autor mantuvo vigentes hasta su ensayo final:

Plus que jamais, messieurs, nous devons nous occuper de ces hautes spéculations, car il faut nous tenir prêts pour un événement immense dans l'ordre divin, vers lequel nous marchons avec une vitesse accélérée qui doit frapper tous les observateurs. Il n'y a plus de religion sur 
la terre : le genre humain ne peut demeurer dans cet état. Des oracles redoutables annoncent d'ailleurs que les temps sont arrivés. [...] N'est-ce rien que ce cri général qui annonce de grandes choses ? (De Maistre, 1886: 234).

La interrogación retórica del senador proyecta al lector de estas líneas hacia un tiempo futuro donde se confirmará el plan divino de una Providencia que sigue podando a su antojo el árbol del género humano, tal y como ya visualizó otra de las analogías iniciales de Considérations sur la France. Así pues, ensayo tras ensayo, Joseph de Maistre no hizo más que clamar y proclamar que la ilimitada acción de la Providencia es el vórtice de la espiral que envuelve la Historia. Incluso a día de hoy, quizás algún lector tenga la impresión, al acercarse a las páginas del saboyano, que dicha espiral ha seguido y sigue moviéndose sin descanso.

\section{REFERENCIAS BIBLIOGRÁFICAS}

ARMENTEROS, Carolina (2018): L'idée française de l'histoire. Joseph de Maistre et sa postérité (1794-1854). París, Classiques Garnier.

ARMOGATHE, Jean-Robert (2012): «Le prophétisme chrétien, de l'inquiétude à la Révolution (XVe-XVIII ${ }^{\mathrm{e}}$ siècles)», in A. Vauchez (ed.), Prophètes et prophétisme. París, Seuil, 127-143.

BARBey D’Aurevilly, Jules (1851): Les Prophètes du passé. París, Louis Hervé éditeur. Disponible en: htpp://gallica.bnf.fr/ark:/12148/bpt6k111302c.texteImage.

BAUdelaire, Charles (2016 [1887]): Fusées. Mon cœur mis à nu et autres fragments posthumes. París, Gallimard (coll. Folio Classique).

BERLIN, Isaiah (1992) El fuste torcido de la humanidad. Capítulos de historia de las ideas. Traducción de José Manuel Álvarez Flórez. Barcelona, Ediciones Península.

Bernanos, Georges (1931): La Grande Peur des Bien-Pensants. París, Librairie Générale Française (coll. Le Livre de Poche).

BOUTRY, Philippe (2012): «Le prophétisme de la Révolution à la Grande Guerre (1789-1914)», in A. Vauchez (ed.), Prophètes et prophétisme. París, Seuil, 205-285.

CIORAN, Émile (1977). Essai sur la pensée réactionnaire. París, Fata Morgana.

COMPAGNON, Antoine (2005): Les Antimodernes: de Joseph de Maistre à Roland Barthes. París, Gallimard.

FOUlQUié, Paul (1978): Vocabulaire des Sciences sociales. París, Presses Universitaires de France. Disponible en: https://gallica.bnf.fr/ark:/12148/bpt6k48071289/f18.item.texteImage. 
FREUND, Julien (1982): «Considérations sur prophétisme et politique». Revue d'histoire et de philosophie religieuses, 4, 373-383. Disponible en: https://www.persee.fr/doc/rhpr_0035-2403_1982_num_62_4_4680.

FREUND, Julien (1990): «Prophétisme», in Encyclopaedia Universalis. París, Encyclopaedia Universalis, Corpus 19, 62-64.

GIBERT, Pierre (2012): «Le prophétisme biblique», in A. Vauchez (ed.), Prophètes et prophétisme. París, Seuil, 21-60.

LABARTHE, Patrick (1999): Baudelaire et la tradition de l'allégorie. Ginebra, Droz.

MAISTRE, Joseph de (1872 [1793]): Lettres d'un royaliste savoisien à ses compatriotes publiées, pour la première fois, en France d'après l'original, très rare, de l'année 1793. París-Lyon, Pélagaud fils et Roblot. Disponible en: https://gallica.bnf.fr/ark:/12148/bpt6k62577457.texteImage.

MAISTRE, Joseph de (1886 [1797, 1819, 1821, 1851]): CEuvres.complètes de Joseph de Maistre. Tomos I, II, IV y XIV. Lyon, Vitte et Perrussel. Disponible en: htpp://gallica.bnf.fr/ark:/12148/bpt6k5781124z.texteImage; httpp://gallica.bnf.fr/ark:/12148/bpt6K57812620.texteImage; http:/gallica.bnf.fr/ark:/12148/bpt6k57812620.texteImage.

MAISTRE, Joseph de (2007): Joseph de Maistre. Euvres. Edición de Pierre Glaudes. París, Robert Laffont (coll. Bouquins).

MAISTRE, Joseph de (2015): Consideraciones sobre Francia. Estudio introductorio de María Luisa Guerrero. Madrid, Escolar y Mayo (coll. Hitos).

Sagrada Biblia. Antiguo y Nuevo Testamento. Traducción de Eloíno Nácar y Alberto Colunga. Madrid, Biblioteca de Autores Cristianos, La Editorial Católica, 1973 [1969].

SAINTE-BEUVE, Charles-Augustin de (1862): Portraits littéraires. París, Garnier Frères. Tomo II. Disponible en: htpp://gallica.bnf.fr/ark:/12148/bpt6k35430t/f3.item.

SICRE, José Luis (2012): Introducción al profetismo bíblico. Madrid, Editorial Verbo divino.

SOLLERS, Philippe (2010) «Éloge d'un maudit». Disponible en: http://www.philippesollers.net/Maistre.html.

Trebolle, Julio (2000): Imagen y palabra de un silencio: la Biblia en su mundo. Madrid, Trotta.

WEBER, Max (2014 [1922]): Economía y Sociedad. Edición y Traducción de Francisco Gil Villegas. Méjico (D.F), Fondo de Cultura Económica. Disponible en: https://ellibro.net/es/reader/universidadcomplutense/111146. 